\title{
RETENTION BEHAVIOUR OF AROMATIC HYDROCARBONS IN REVERSED-PHASE HPLC BASED ON PHENYL-SILICA STATIONARY PHASE
}

\author{
Edvin CAIALI and Victor DAVID* \\ University of Bucharest, Faculty of Chemistry, Department of Analytical Chemistry, Sos. Panduri, \\ No. 90, 050663, Bucharest, Roumania
}

Received November 19, 2018

Retention behaviour of five aromatic hydrocarbons (from benzene to butylbenzene) was studied by reversed-phase liquid chromatography using three different columns loaded with phenyl-silica based stationary phase. Retention factor for these solutes was measured for different mobile phase compositions and its dependences on the content in organic modifier (methanol or acetonitrile) in the mobile phase were used in estimating the extrapolated values of the retention factor corresponding to water as mobile phase $\left(k_{\mathrm{w}}\right)$. The correlations between the values of $\log k_{\mathrm{w}}$ and the values of octanol/water partition constant $\left(\log K_{\text {ow }}\right)$ of the studied hydrocarbons were characterized by high correlation coefficients. A good correlation between carbon content of the stationary phases and the retention factors for the studied hydrocarbons was observed in both situations by using methanol or acetonitrile as organic solvent in the mobile phase. Also, very good correlations between the values of the water solubility of the studied hydrocarbon $\left(\log S_{\mathrm{w}}\right)$ and the values of extrapolated retention factor $(\log$ $k_{\mathrm{w}}$ ), for both organic modifiers, have been observed.

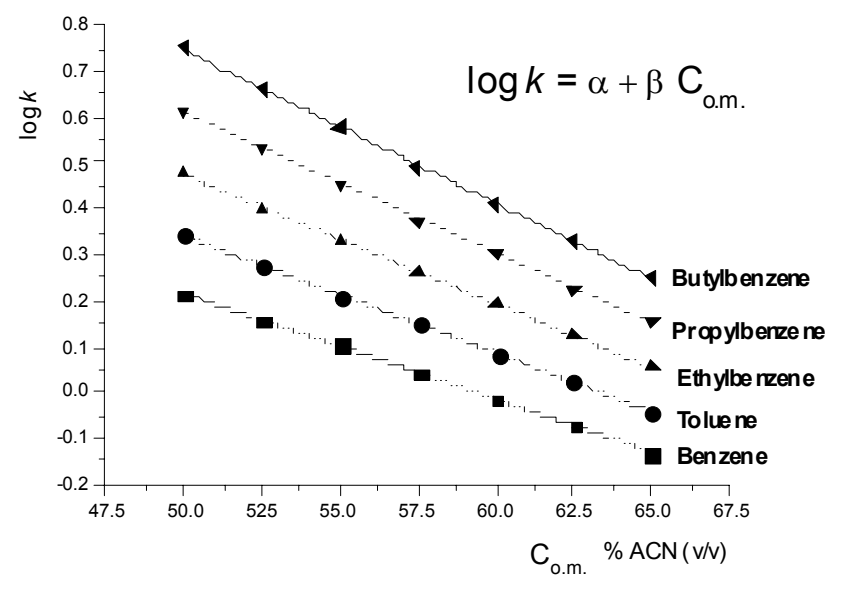

may influence the selectivity of separation on both cyano and phenyl columns, but this parameter is also influenced by the nature of the organic modifier added to the mobile phase. ${ }^{3,4}$ In case of cyanopropyl-silica as stationary phase, polar interactions between solute dipole and cyano dipole are also involved into the retention mechanism. ${ }^{5,6}$

Affinity of aromatic compounds for phenylsilica based stationary phase may lead not only to the control of their separation selectivity, ${ }^{7}$ but it may be exploited by injecting high volume of

\footnotetext{
${ }^{*}$ Corresponding author: victor.david@chimie.unibuc.ro
} 
aromatic solvents for enhancing detectability in HPLC with spectrometric detection. ${ }^{8}$ However, other studies have shown that the interaction between aromatic structures are conditioned by certain geometrical requirements, and consequently the net favorable $\pi-\pi$ interactions are actually the result of $\pi-\sigma$ atractions that is overcoming to $\pi-\pi$ repulsions. ${ }^{9}$ On the other hand, the interactions between aromatic compounds with components of the mobile phase may influence tremendously the energetic balance of the retention mechanism, and consequently the retention behaviour of the distributed species. ${ }^{2}$ Hydration of these solutes is also a typical interaction in mobile phase, due to the $\pi$-water hydrogen-bonding, ${ }^{10}$ which contributes to the energetics of the retention process. For example, according to the definition given by Ben-Naim, ${ }^{11}$ the hydration free energy, considered as the free energy change associated with the transfer of the solute molecule from gas to water, calculated for two of the studied hydrocarbons, ${ }^{10}$ namely benzene and toluene, were -4.76 and $-3.01 \mathrm{~kJ} / \mathrm{mol}$, respectively. This is of the same magnitude with the free energy change associated with the RP-LC retention mechanism. ${ }^{2}$

The aim of this study is to compare the retention of a group of five aromatic hydrocarbons on three different columns loaded with phenylsilica stationary phase for mobile phases containing two of the common organic solvents used in RP-LC (methanol, and acetonitrile). For this purpose, the functional dependences between the retention factor measured for these hydrocarbons and the organic solvent content in mobile phase were studied, and used in correlating the retention of these hydrocarbons with the characteristics of the used LC columns.

\section{EXPERIMENTAL}

The HPLC experiments were carried out with a Perkin Elmer LC system, model Flexar (Waltham, SUA), consisting of the following components: degasser, quaternary pump with low pressure mixing, autosampler, column thermostatted compartment, and variable UV wavelength detector. Data acquisition was achieved by means of Perkin Elmer Chromera CDS software. The columns used in this study and some of their characteristics are described in Table 1. All commercial columns have been loaded with phenyl-silica stationary phase, and they were new and tested before usage according to the manufacturer specifications.

A standard mixture of benzen, toluene, ethylbenzene, propylbenzen, and butylbenzen at $100 \mu \mathrm{g} / \mathrm{mL}$ was prepared in methanol using pure substances. Injections of $1 \mu \mathrm{L}$ of this mixture were used to measure the retention time of each hydrocarbon and the spectrometric detection was made at $254 \mathrm{~nm}$. The chromatograpic column was kept constant at $25^{\circ} \mathrm{C}$. Each experimental run was repeated three times and the average retention times were used for further calculations.

The chromatographic runs were performed using a binary mobile phase: aqueous component consisting of water and organic component (methanol or acetonitrile). For both systems the proportion of organic solvent in mobile phase composition was varied in steps of $2.5 \%$ (in the range of 50 $65 \%$ for acetonitrile and $60-75 \%$ for methanol). The mobile phase for each solvents proportion was generated using pure solvents and the appropriate settings for the pump (the solvents were not premixed).

The retention factor $k$ was calculated for each studied hydrocarbon with the formula $k=\left(\mathrm{t}_{\mathrm{r}}-\mathrm{t}_{0}\right) / \mathrm{t}_{0}$, where the $\mathrm{t}_{\mathrm{r}}$ represents the retention time for the hydrocarbon, and $t_{0}$ represents the dead time of the separation, which was measured from the retention time of uracil under the same chromatographic conditions as applied to the studied hydrocarbons.

\section{RESULTS AND DISCUSSION}

A major parameter that influences the chromatographic selectivity for reversed-phase based on phenyl-silica stationary phase is the mobile phase composition. ${ }^{\mathbf{1 2}}$ The retention of benzene, toluene, ethylbenzene, propylbenzen and butylbenzene was studied for the two organic modifiers in mobile phase composition, within the following intervals: $50-65 \%(\mathrm{v} / \mathrm{v})$ for acetonitrile, and $60-75 \%(\mathrm{v} / \mathrm{v})$ for methanol. Their retention dependences, namely the ten-base logarithm of the experimental retention factor $k$ versus the organic modifier content in mobile phase composition $\left(C_{\text {o.m. }}\right)$, followed a linear function ${ }^{13}$ described by the equation (Soczewinski-Snyder):

$$
\log \mathrm{k}=\alpha+\beta \cdot \mathrm{C}_{\mathrm{o} . \mathrm{m}}
$$

Table 1

The chromatographic columns used in this study, and some of their characteristics

\begin{tabular}{l|c|c|c|c|c}
\hline \multicolumn{1}{c|}{ Column type } & End-capping & $\begin{array}{c}\text { Geometric characteristics } \\
\text { length }(\mathrm{mm}) \times \text { i.d. }(\mathrm{mm}) \times \\
\text { particles diameter }(\mu \mathrm{m})\end{array}$ & $\begin{array}{c}\text { Carbon } \\
\text { load } \\
(\%)\end{array}$ & $\begin{array}{c}\text { Surface area } \\
\left(\mathrm{m}^{2} / \mathrm{g}\right)\end{array}$ & $\begin{array}{c}\text { Pore } \\
\text { size } \\
(\AA)\end{array}$ \\
\hline Zorbax Eclipse, XDB-Phenyl & $\begin{array}{c}\text { Double } \\
\text { Phenomenex Gemini, C6-Phenyl }\end{array}$ & $\begin{array}{l}150 \times 4.6 \times 5 \\
150 \times 4.6 \times 5\end{array}$ & 1.2 & 180 & 80 \\
PerkinElmer Brownlee Analytical, & End-capped & $150 \times 4.6 \times 5$ & 6 & 375 & 110 \\
Phenyl PE & n.d.a.* & 110 \\
\hline
\end{tabular}

* n.d.a. indicates no data available. 
The parameters $\alpha$ and $\beta$ were calculated from linear regressions applied to the retention data obtained for each studied compound, as the dependence between experimental values of $\log k$ and $C_{o . m .}$. These linear dependences that are typically obtained in reversed-phase HPLC were characterized by high correlation coefficients $\left(\mathrm{r}^{2}>\right.$ 0.9900). An example of the linear dependences obtained for the five studied hydrocarbons using Zorbax Phenyl chromatographic column and acetonitrile as organic modifier in the mobile phase composition is given in Fig. 1. Overall, the regression parameters calculated for the studied hydrocarbons by using the two organic modifiers and the three chromatographic columns are given in Tables 2, 3 and 4.

Two main conclusions from the experimental data are following:

In all cases the retention of studied hydrocarbons were higher for methanol than acetonitrile, added at the same volumetric concentration in mobile phase (a comparison between the dependences obtained for the two organic modifiers is depicted in Fig. 2); the supposition that acetonitrile impedes the $\pi-\pi$ interaction between aromatic hydrocarbons and phenyl group from stationary phase ${ }^{4}$ could be valid as these compounds do not contain other functional groups for being involved in other interactions with the components in mobile phase.

The three chromatographic columns showed different retention behavior for the studied hydrocarbons, which can be assigned to different phase ratio characterizing these columns $\left(k=\phi_{\text {column }} \cdot K\right.$, where $\phi_{\text {column }}$ represents the ratio between stationary phase volume and mobile phase volume, while $K$ representing the partition constant for the studied hydrocarbon between mobile phase and stationary phase that is assumed to be the same for all three columns $^{2}$ ). An example is given in Fig. 3 for butylbenzene using methanol as organic modifier for the three studied columns.
The parameter $\alpha$ from the above dependence represents the logarithm of the retention factor of the hydrocarbon, extrapolated to a mobile phase consisting in water only $\left(C_{\text {o.m. }}=0\right)$, denoted by log $k_{w}\left(\alpha=\log k_{w}\right)$. In RP-LC based on octyl or octadecyl-silica stationary phases, the value of $\log k_{w}$ is usually correlated to the octanol/water partition constant $\left(\log K_{o w}\right)$, due to the similarity between the two immiscible phases, namely octanol/water system and mobile phase/stationary phase system. In our case, owing to the nature of the phenyl stationary phase, the extrapolated value of the retention factor, $\log k_{w}$, is expected to be correlated with the benzene/water $\left(K_{\mathrm{C} 6 \mathrm{H} / \mathrm{w} / \mathrm{w}}\right){ }^{14}$ or toluene/water partition constant $\left(K_{\mathrm{C} 6 \mathrm{H} 5 \mathrm{CH} 3 / \mathrm{w}}\right)$. However, the lack of distribution data on these two immiscible systems does not allow finding out such correlations. But, many studies from the literature carried out under RP-LC separation using octyl, octadecyl, phenyl or cyanopropyl-silica as stationary phase have shown that the value of $\log k_{w}$ is almost always correlated to $\log K_{\text {ow }}$, due to the hydrophobic forces involved into the retention mechanism. ${ }^{8,15-17}$ This is convenient because there are available data, ${ }^{18}$ both theoretical and experimental values for the system octanol/water, as indicated in Table 5. Linear correlations between $\log k_{w}$ and the theoretical or experimental $\log K_{\text {ow }}$ from this table were characterized by acceptable correlation coefficients $\left(\mathrm{r}^{2}\right)$, which were higher than 0.9900 .

Usually, the benzene/water partition constant of a distributed species $\left(K_{\mathrm{C} 6 \mathrm{H} 6 / \mathrm{w}}\right)$ can be related to its water solubility $\left(S_{\mathrm{w}}\right.$ as mole/L). ${ }^{2,14}$ In this study, a very good correlation between the values of $\log S_{\mathrm{w}}$ of the studied hydrocarbons calculated with EPI Suite computer package ${ }^{18}$ and the values of extrapolated retention factor $\left(\log k_{\mathrm{w}}\right)$, for both organic modifiers from the Tables $2-4$, has been observed. An example for the Brownlee Phenyl PE column is illustrated in Fig. 4, where correlations coefficients $r^{2}$ higher than 0.9900 can be noticed.

Table 2

Regression parameters calculated for the five aromatic hydrocarbon by means of eq. 1, studied for Brownlee Phenyl PE chromatographic column

\begin{tabular}{l|c|c|c|c|c|c}
\hline \multirow{2}{*}{ Compound } & $\begin{array}{c}\text { Intercept } \\
(\alpha)\end{array}$ & $\begin{array}{c}\text { Slope } \\
(\beta)\end{array}$ & $\begin{array}{c}\text { Correlation } \\
\text { coefficient }\left(\mathrm{r}^{2}\right)\end{array}$ & $\begin{array}{c}\text { Intercept } \\
(\alpha)\end{array}$ & $\begin{array}{c}\text { Slope } \\
(\beta)\end{array}$ & $\begin{array}{c}\text { Correlation } \\
\text { coefficient }\left(\mathrm{r}^{2}\right)\end{array}$ \\
\cline { 2 - 7 } & \multicolumn{3}{|c}{ Organic modifier: Acetonitrile } & \multicolumn{2}{c}{ Organic modifier: Methanol } \\
\hline Benzene & 1.308 & -0.0225 & 0.9983 & 1.349 & -0.0242 & 0.9992 \\
Toluene & 1.550 & -0.0250 & 0.9985 & 1.693 & -0.0271 & 0.9992 \\
Ethylbenzene & 1.806 & -0.0275 & 0.9986 & 2.040 & -0.0302 & 0.9991 \\
Propylbenzene & 2.068 & -0.0301 & 0.9985 & 2.425 & -0.0338 & 0.9991 \\
Butylbenzene & 2.324 & -0.0326 & 0.9984 & 2.875 & -0.0382 & 0.9980 \\
\hline
\end{tabular}




\section{Table 3}

Regression parameters calculated for the five aromatic hydrocarbon by means of eq. 1, studied for Zorbax Phenyl chromatographic column

\begin{tabular}{l|c|c|c|c|c|c}
\hline \multirow{2}{*}{ Compound } & $\begin{array}{c}\text { Intercept } \\
\end{array}$ & $\begin{array}{c}\text { Slope } \\
(\alpha)\end{array}$ & $\begin{array}{c}\text { Correlation } \\
\text { coefficient }\left(\mathrm{r}^{2}\right)\end{array}$ & $\begin{array}{c}\text { Intercept } \\
(\alpha)\end{array}$ & $\begin{array}{c}\text { Slope } \\
(\beta)\end{array}$ & $\begin{array}{c}\text { Correlation } \\
\text { coefficient }\left(\mathrm{r}^{2}\right)\end{array}$ \\
\cline { 2 - 7 } & \multicolumn{3}{|c}{ Organic modifier: Acetonitrile } & \multicolumn{3}{c}{ Organic modifier: Methanol } \\
\hline Benzene & 1.365 & -0.0230 & 0.9999 & 1.642 & -0.0268 & 0.9900 \\
Toluene & 1.613 & -0.0254 & 0.9999 & 2.115 & -0.0310 & 0.9944 \\
Ethylbenzene & 1.876 & -0.0280 & 0.9998 & 2.530 & -0.0348 & 0.9970 \\
Propylbenzene & 2.147 & -0.0307 & 0.9996 & 3.054 & -0.0399 & 0.9981 \\
Butylbenzene & 2.412 & -0.0333 & 0.9992 & 3.610 & -0.0454 & 0.9987 \\
\hline
\end{tabular}

Table 4

Regression parameters calculated for the five aromatic hydrocarbon by means of eq. 1 , studied for Phenomenex Phenyl chromatographic column

\begin{tabular}{l|c|c|c|c|c|c}
\hline \multirow{2}{*}{ Compound } & $\begin{array}{c}\text { Intercept } \\
(\alpha)\end{array}$ & $\begin{array}{c}\text { Slope } \\
(\beta)\end{array}$ & $\begin{array}{c}\text { Correlation } \\
\text { coefficient }\left(\mathrm{r}^{2}\right)\end{array}$ & $\begin{array}{c}\text { Intercept } \\
(\alpha)\end{array}$ & $\begin{array}{c}\text { Slope } \\
(\beta)\end{array}$ & $\begin{array}{c}\text { Correlation } \\
\text { coefficient }\left(\mathrm{r}^{2}\right)\end{array}$ \\
\cline { 2 - 7 } & \multicolumn{3}{|c}{ Organic modifier: Acetonitrile } & \multicolumn{3}{c}{ Organic modifier: Methanol } \\
\hline Benzene & 1.619 & -0.0235 & 0.9992 & 2.032 & -0.0279 & 0.9991 \\
Toluene & 1.928 & -0.0264 & 0.9988 & 2.534 & -0.0323 & 0.9993 \\
Ethylbenzene & 2.249 & -0.0295 & 0.9983 & 3.040 & -0.0369 & 0.9995 \\
Propylbenzene & 2.592 & -0.0327 & 0.9977 & 3.612 & -0.0423 & 0.9996 \\
Butylbenzene & 2.925 & -0.0357 & 0.9971 & 4.190 & -0.0477 & 0.9997 \\
\hline
\end{tabular}

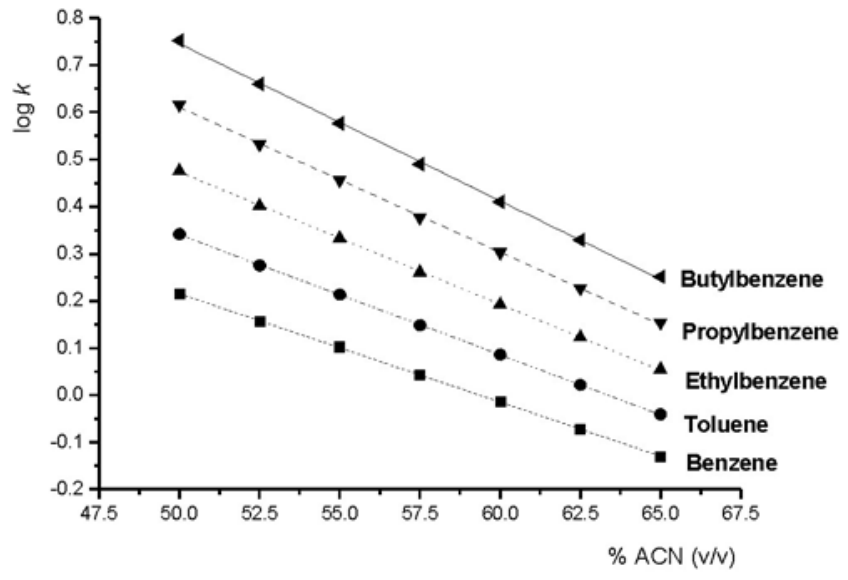

Fig. 1 - Comparison between the retention depedences of the five aromatic hydrocarbons obtained for the acetonitrile as organic modifier in mobile phase and Zorbax Phenyl chromatographic column.

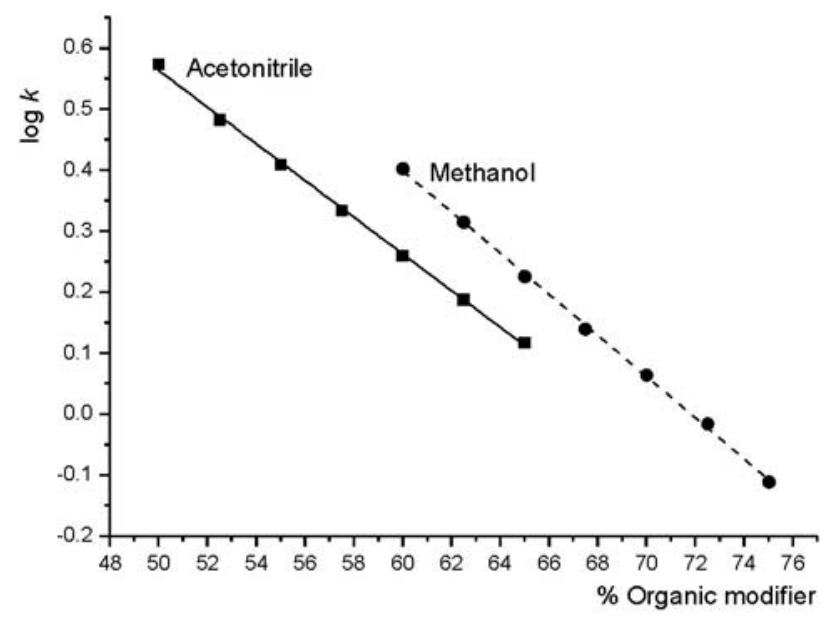

Fig. 2 - Comparison between the retention dependences of propylbenzene for Phenomenex column and the two organic modifiers used in this study. 


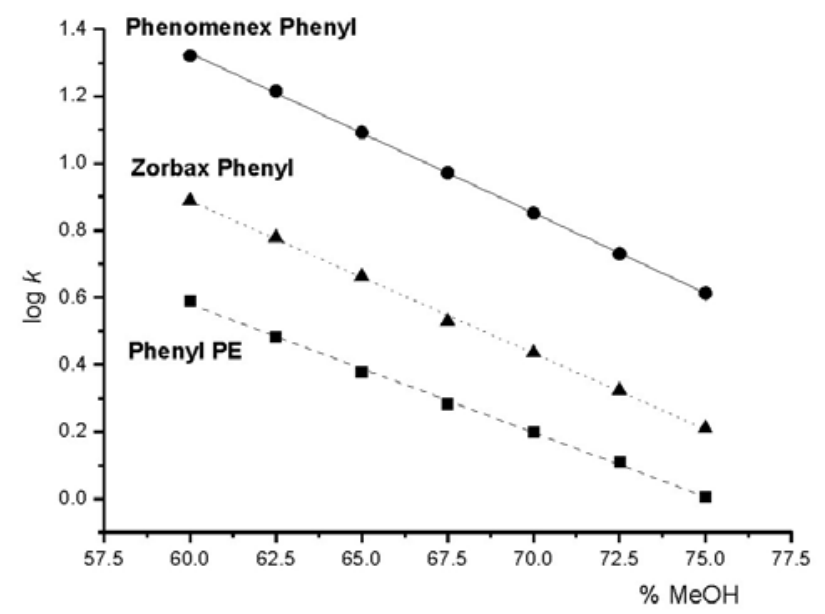

Fig. 3 - Comparison between the retention dependences of butylbenzene for methanol as organic modifier and the three studied columns.

Table 5

Data on the octanol/water partition constant $\left(\log K_{\text {ow }}\right)$ of studied hydrocarbons

\begin{tabular}{l|c|c}
\hline \multicolumn{1}{c|}{ Hydrocarbon } & $\begin{array}{c}\text { Theoretical } \\
\log K_{\text {ow }}\end{array}$ & $\begin{array}{c}\text { Experimental } \\
\log K_{\text {ow }}\end{array}$ \\
\hline Benzene & 1.99 & 2.13 \\
Toluene & 2.54 & 2.73 \\
Ethylbenzene & 3.03 & 3.15 \\
Propylbenzene & 3.52 & 3.69 \\
Butylbenzene & 4.01 & 4.38 \\
\hline
\end{tabular}

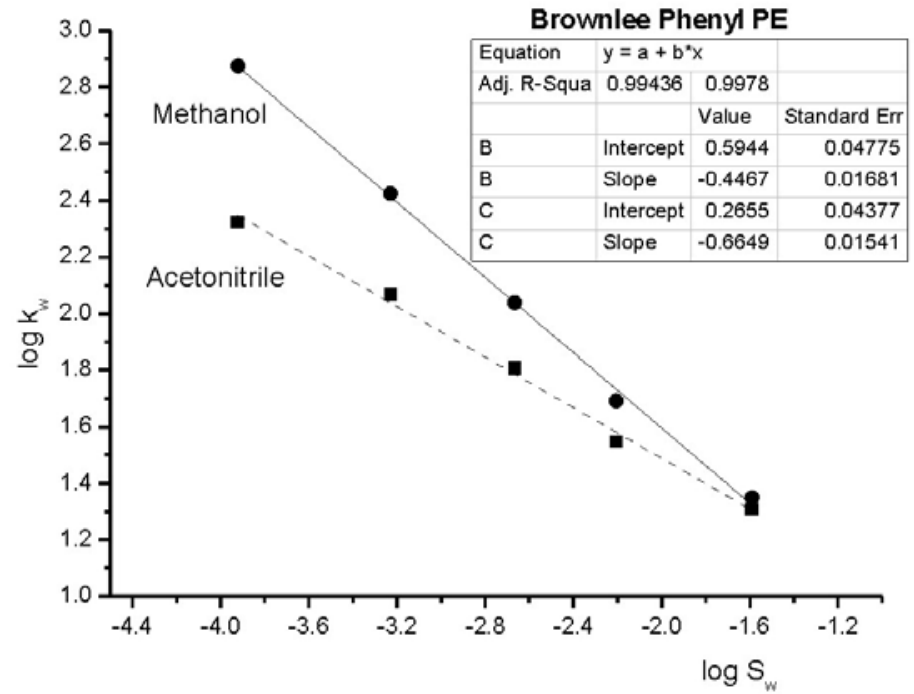

Fig. 4 - Linear correlation between the extrapolated values of the retention factor $\left(\log k_{\mathrm{w}}\right)$

for the two organic modifiers in mobile phase and the logarithm of water solubility $\left(\log S_{\mathrm{w}}\right)$ of studied hydrocarbons.

As previously emphasized, the retention factor is directly proportional to the column phase ratio $\phi_{\text {column }}$. The volume of stationary phase involved in the retention mechanism can be correlated in a very fair aproximation with the $\mathrm{C}$ load (\%) of the stationary phase. According to the data from Table 1 , the decreasing order of the carbon load of the three used LC columns are following: Phenomenex
$>$ Zorbax Eclipse $>$ Brownlee Phenyl PE. The values of the extrapolated parameter $\log k_{\mathrm{w}}$, as the main parameter describing the partition of hydrocarbon between the mobile phase and the stationary phase, followed this rule for all five studied hydrocarbons, and the two organic modifiers (Tables 2-4). Moreover, the values of C load from Table 1 are fairly correlated to the 
values of $\log k_{\mathrm{w}}$ for all studied hydrocarbons and the two organic solvents, with $r^{2}>0.9000$.

\section{CONCLUSIONS}

Retention study of five aromatic hydrocarbons (from benzene to butylbenzene) on three LC columns containing phenyl-silica stationary phase showed that their retention behaviour is dependent on the nature of the organic solvent (modifier) added to the mobile phase. The highest retention factor was measured for methanol compared to acetonitrile, and the calculated values of the extrapolated retention factor for mobile phase containing only water $\left(k_{\mathrm{w}}\right)$ were very well correlated to the values of octanol/water partition constants $\left(K_{\text {ow }}\right)$ for the studied hydrocarbons. Also, good correlations between $\log k_{\mathrm{w}}$ and carbon load of the three chromatographic columns were observed for all studied hydrocarbons and the two organic solvents (acetonitrile, and methanol).

\section{REFERENCES}

1. G. Thevenon-Emeric, A. Tchapla and M. Martin, J. Chromatogr. A, 1991, 550, 267-283.

2. S. C. Moldoveanu and V. David, "Essentials in Modern HPLC Separations”, Elsevier, Amsterdam, 2014.
3. K. Croes, A. Steffens, D. H. Marchand and L. R. Snyder, J. Chromatogr. A, 2005, 1098, 123-130.

4. M. Yang, S. Fazio, D. Munch and P. Drumm, J. Chromatogr. A, 2005, 1097, 124-129.

5. M. G. Kouskoura, D. Hadjipavlou-Litina and C. K. Markopoulou, J. Sep. Sci., 2014, 37, 1919-1929.

6. V. David, N. Grinberg and S. C. Moldoveanu, $A d v$. Chromatogr., 2018, 54, 77-110.

7. P. Stepnowski, J. Nichthauser, W. Mrozik and B. Buszewski, Anal. Bioanal. Chem., 2006, 385, 1483-1491.

8. T. Galaon, E. Bacalum, M. Cheregi and V. David, J. Chromatogr. Sci., 2013, 51, 166-172.

9. C. A. Hunter and J. K. M. Sanders, J. Amer. Chem. Soc, 1990, 112, 5525-5534.

10. H. Lee, H.-K. Lim and H. Kim, Molecules, 2018, 23, article number 2927.

11. A. Ben-Naim, J. Phys. Chem., 1978, 82, 792-803.

12. M. Yang, S. Fazio, D. Munch and P. Drumm, J. Chromatogr. A, 2005, 1097, 124-129.

13. E. Soczewinski and C. A. Wachtmeister, J. Chromatogr., 1962, 7, 311-320.

14. J. Petre, V. Iancu and V. David, Rev. Roum. Chim., 2009, 54, 259-264.

15. J. L. G. Thus and J. C. Kraak, J. Chromatogr. A, 1985, 320, 271-279.

16. C. R. Clark, J. M. Barksdale, C. A. Mayfield, W. R. Ravis and J. DeRuiter, J. Chromatogr. Sci., 1990, 28, 83-87.

17. J. Petre, R. D. Nascu-Briciu, V. Iancu, V. David and C. Sârbu, J. Liq. Chromatogr. Rel. Technol., 2011, 34, 289-306.

18. https://www.epa.gov/tsca-screening-tools/download-episuitetm-estimation-program-interface-v411. 